\title{
Condylar Growth in Rhesus Monkeys
}

MARVIN C. KANOUSE, SIGURD P. RAMFJORD, and CARLOS E. NASJLETI

Department of Periodontics School of Dentistry, University of Michigan, and Veterans Administration Hospital, Ann Arbor, Michigan 48104

Growth of the mandibular condyle was studied in four rhesus monkeys of different ages. Indexes of ${ }^{3} \mathrm{H}$-thymidine labeling indicated high premitotic activity, which decreased with age, in the intermediate zone of cartilage and the zone of erosion and bone formation. Premitotic uptake in the articular zone was independent of age.

The advent of autoradiography has made it possible to add information on cellular dynamics to histologic observations of morphologic details reported in previous studies. $^{1-5}$ Condylar growth has been studied extensively in rodents by autoradiographic technics. ${ }^{6-9}$ Since the temporomandibular joint and masticatory function in the rhesus monkey more clearly resemble the human situation, cellular dynamics in condylar growth as well as normal adult function in rhesus monkeys were studied. Autoradiography after administration of tritiated thymidine was used for this purpose.

\section{Materials and Methods}

A $4 \frac{1}{2} 2$-month-old baby rhesus monkey (Macaca mulatta) with some erupted deciduous teeth, a rhesus monkey approximately 3 years old with a mixed dentition, ${ }^{10}$ and a pregnant adult rhesus monkey (all permanent teeth fully erupted) carrying a 4-month fetus were used in this study. No dental treatment was performed on any of the monkeys.

The pregnant adult and the 3-year-old monkey were anesthetized with sodium pentobarbital, and 1 microcurie $(\mu \mathrm{c})$ of tritiated thymidine (specific activity 6.7 curies/millimole)/gm of body weight was administered intravenously. The baby monkey was given $1 \mu \mathrm{c}$ of tritiated thymidine/gm of body weight by intraperitoneal injection.

Received for publication June 21, 1968.
The baby monkey and the 3-year-old monkey were killed one hour and 15 minutes after injection of the isotope. The adult rhesus monkey was killed one hour and 42 minutes after injection of the isotope. Sections and autoradiographs were prepared according to previously published methods. ${ }^{11}$ All the temporomandibular joints (including those of the fetus) were serially sectioned, and autoradiographs were prepared from three of every ten sections. One autoradiograph of every six in sequence was used to determine a radioactive index. The condyle was divided into five zones (Fig 1) to facilitate cell counting: Zone 1 is the articular zone, limited to the fibrous covering of the condyle. Zone 2 is the intermediate zone; undifferentiated cells are located below the fibrous covering of the condyle and immediately above the area of interstitial growth of cartilage cells. Zone 3 is the zone of differentiation and interstitial growth of cartilage cells, located immediately below the intermediate zone. Zone

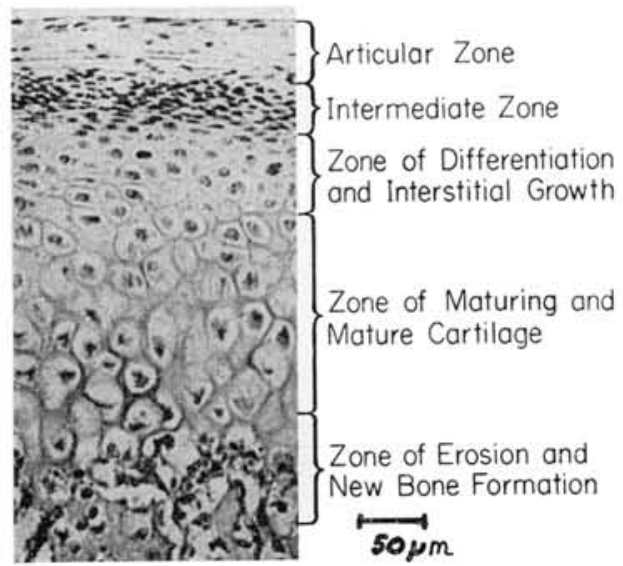

FIG 1.-Section through the condyle of baby monkey. The five zones used for cell counts are shown (orig mag $\times 230$ ). 
4 is the zone of maturing cartilage, which extends from zone 3 and contains maturing and mature chrondrocytes. Zone 5 is the zone of erosion of cartilage and new bone formation, which is the boundary area between bone and cartilage. It is characterized by calcification and replacement of cartilage by bone.

The validity of separating the condyle into growth zones was checked by counting labeled cells from five selected slides/condyle according to the coordinate system. This was done by placing a grid over the autoradiographs (Whipple micrometer disk) and recording the number and position of labeled cells relative to the grid. A mechanical stage with vertical and horizontal coordinates was used to record the position of each labeled cell, and the distribution of the labeled cell was plotted according to this coordinate system. Thus, zones of radioactivity relative to the growth zones of the condyle were obtained independent of the microanatomy of the condyle.

\section{Results}

Few labeled cells appeared in the articular zone (zone 1), regardless of the age of the monkey. The labeled cells were sporadically distributed and too few in number for computation of a radioactivity index. In contrast to the sparse labeling in the articular zone, the intermediate zone (zone 2) showed a high radioactive index (Table 1). It was easy to separate these two zones (Fig 2) on the basis of labeling, as well as morphology.

The radioactive index of the intermediate zone of the condyle specimens was highest in the fetus (Table 1) and decreased considerably with increase in age. The intermediate zone also was thickest in the fetus (Fig 3,top). This vertical thickness also decreased with increase in (Fig 3, bottom);

TABLE 1

Cell Counts and Radioactive Indexes of the INTERMEDIATE ZONE

\begin{tabular}{lccc}
\hline \hline \multicolumn{1}{c}{ Subjects } & $\begin{array}{c}\text { Total Cells } \\
\text { Counted }\end{array}$ & $\begin{array}{c}\text { Labeled } \\
\text { Cells } \\
\text { Counted }\end{array}$ & $\begin{array}{c}\text { Radioactive } \\
\text { Indexes } \\
(\%)\end{array}$ \\
\hline Fetus & 23,523 & 870 & 3.70 \\
Baby & 19,794 & 223 & 1.12 \\
Mixed dentition & 17,413 & 128 & 0.74 \\
Adult & 20,713 & 81 & 0.39 \\
\hline
\end{tabular}

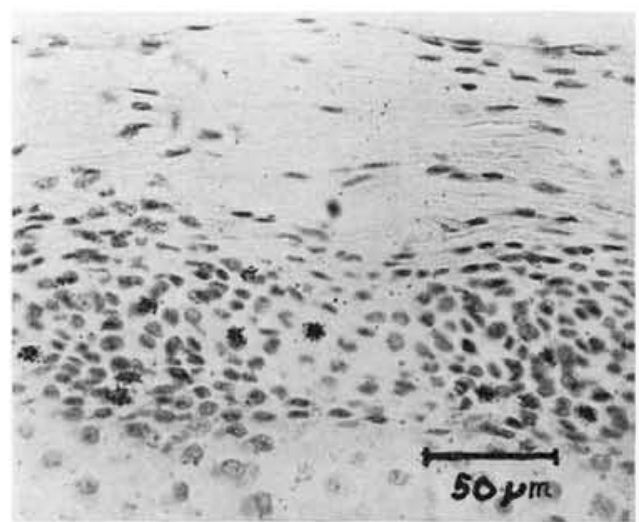

FIG 2.-Higher magnification from same specimen as Figure 1, from articular zone (top) to zone of differentiation (bottom) (orig mag $\times 400)$.

however, the intermediate zone remained a distinct entity in all age groups.

Only two labeled cells were found in the zone of differentiation and interstitial growth of cartilage (zone 3 ). No labeled cells were observed in the zone of mature cartilage (zone 4).

The zone of erosion and new bone formation at each age level (zone 5) showed the highest radioactive index (Table 2). Although the number of labeled cells decreased with age, a relatively high radioactive index was found even in the adult monkey. The majority of the labeled cells were preosteoblasts, but a large number of labeled cells also appeared in adjacent newly forming bone-marrow spaces.

Although the radioactive indexes for the intermediate zone (zone 2) are lower than the indexes for the zone of erosion (zone 5), a comparison of Tables 1 and 2 appears to indicate that the rate of decrease with age is approximately the same for both zones.

The composite of plotted cells, according to the previously described grid method, provides a clear picture of the relative distribution of the labeled cells within the five zones of the condyle (Fig 4, $A, B, C, D$ ). The histograms also illustrate the decided decrease in width of the intermediate zone, which occurred with increased age.

\section{Discussion}

Although there are no well-defined boundaries on a histologic basis ${ }^{12}$ between 


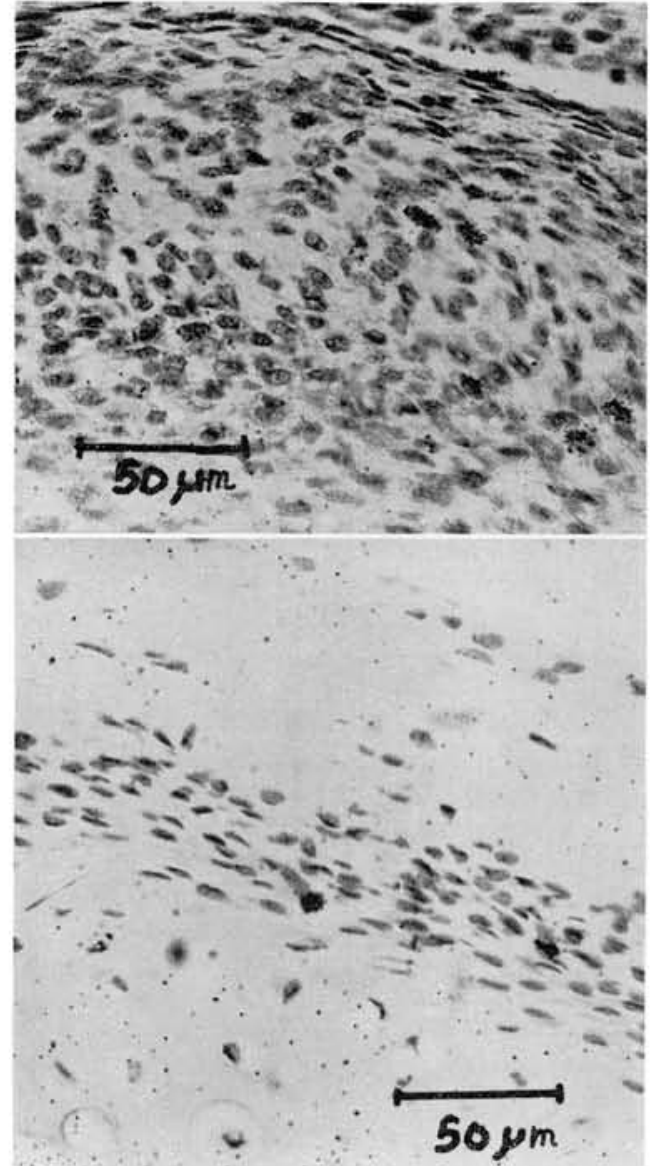

FIG 3.-Top, intermediate zone with wide, labeled cells in fetus. Bottom, intermediate zone that is narrower, with less cellularity, in adult (orig mag $\times 400$ ).

TABLE 2

Cell Counts and Radioactive Indexes of the ZONE OF EROSION

\begin{tabular}{lrcc}
\hline \hline \multicolumn{1}{c}{ Subjects } & $\begin{array}{c}\text { Total Cells } \\
\text { Counted }\end{array}$ & $\begin{array}{c}\text { Labeled } \\
\text { Cells } \\
\text { Counted }\end{array}$ & $\begin{array}{c}\text { Radioactive } \\
\text { Indexes } \\
(\%)\end{array}$ \\
\hline Fetus & 7,290 & 533 & 7.31 \\
Baby & 11,129 & 581 & 5.22 \\
Mixed dentition & 9,369 & 400 & 4.27 \\
Adult & 5,042 & 142 & 2.28 \\
\hline
\end{tabular}

the five separate zones into which the condyle was divided, this division provided a workable basis for comparison of premitotic cell activities.

A small, but relatively constant, number of labeled cells was observed in the articular zone for all age groups. Similar findings were reported previously in rats. ${ }^{6}$ It may be assumed that the few labeled cells represent renewal rather than growth, since the rate of premitotic labeling was independent of age and status of growth. A distinct band of nonlabeled cells and collagen between the articular surface and the intermediate zone was observed, which could indicate separate sites of cell division for the two zones (Fig 5 ), as has been suggested by previous investigators. ${ }^{6-8}$

It has been established by previous investigations that, in rats, ${ }^{2-4,6,8}$ the site of the main growth activity of the condyle is the intermediate zone. This was also found to be true for rhesus monkeys. With completion of growth, there is a decided percentage decrease in premitotic labeling of this zone, which indicates the change from growth to cell renewal needed for maintenance.

Blackwood's ${ }^{6}$ observation that there is a well-defined area of cellular proliferation within the center of the intermediate zone was not supported by the present findings. The shape of the condyle makes the intermediate zone thickest at the center and tapered toward the periphery, which accounts for the decrease in number of labeled cells toward the mesial and distal peripheries. The radioactive indexes in these peripheral regions, however, are not different from the center region.

The border between the intermediate zone and the zone of differentiation and interstitial growth (Fig 1) is not as well demarcated as the border between the intermediate and the articular zone. Only a few labeled cells were seen in this border area between the intermediate and interstitial zones (Fig 6). These few cells may represent early cell migration from the intermediate zone, which occurred during the approximately one-and-one-half-hour period that transpired between the administration of tritiated thymidine and the death of the monkey. No relationship to age and status of growth could be established in these short-term specimens.

The absence of labeled chondrocytes in the zone of maturing and mature cartilage in short-term specimens was reported by Dale et $\mathrm{al}^{7}$ in rats.

High radioactive indexes in the zone of erosion of cartilage and new bone forma- 

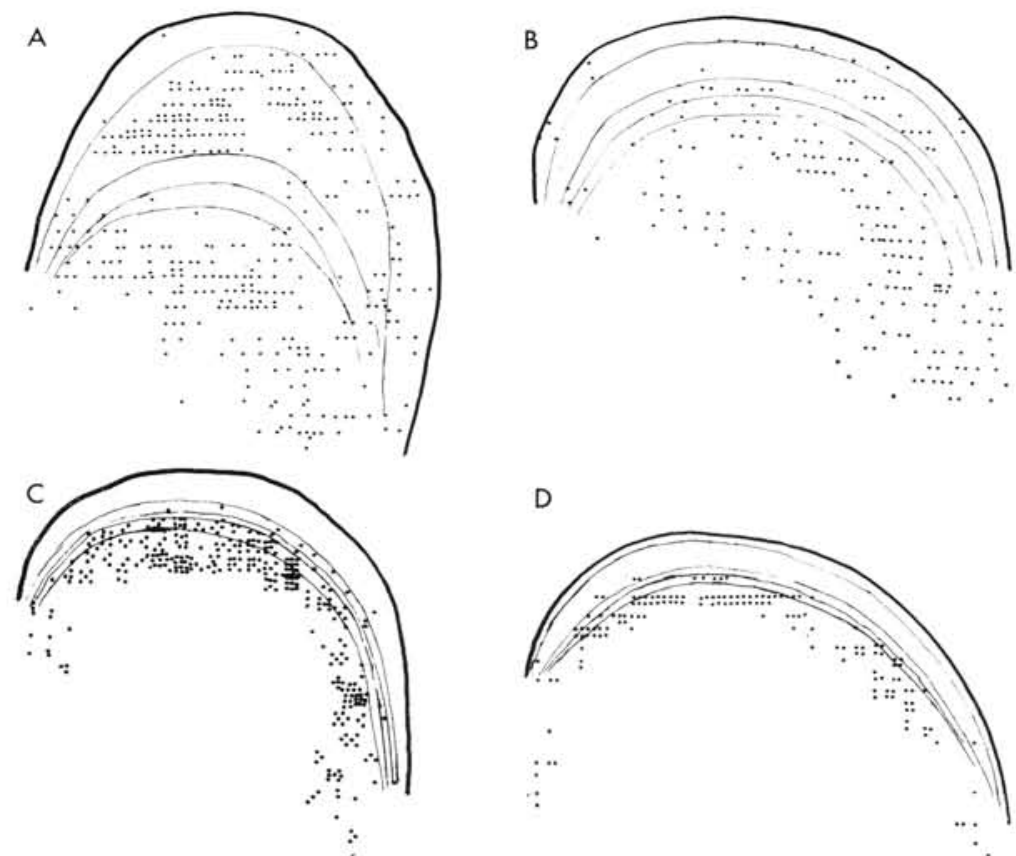

Fig 4.- $A$, histogram from condyle of fetus. Each dot represents two labeled cells. The intermediate zone is represented by the second band under the cap of the condyle. The aggregation of dots under the fourth band represents the zone of erosion and new bone formation. $B$, condyle of baby monkey. The second and fifth bands of dots representing the intermediate zone and the zone of erosion are apparent. There are also a few labeled cells in the first band or articular zone. $C$, condyle of young monkey with mixed dentition. Dots representing the intermediate zone and zone of erosion have approached each other and make schematic separations of zones difficult. $D$, condyle of adult monkey. Zones are narrower, closer together, and less labeling is present.

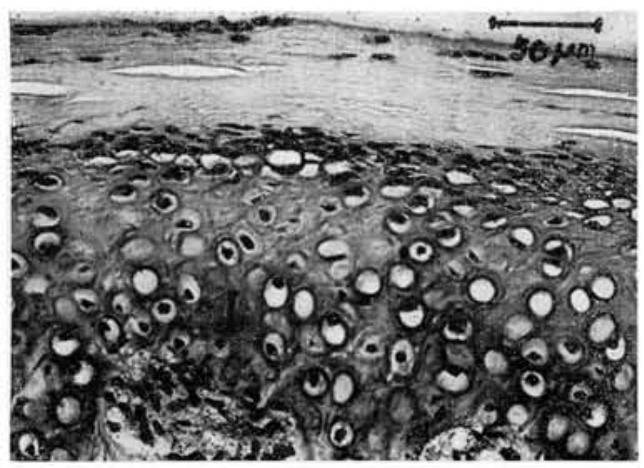

FIG 5.-Condyle of young monkey. Collagenous separation between cells of articular zone and intermediate zone (orig mag $\times 356$ ). tion were mainly associated with labeled preosteoblasts, although in some instances other cells in the marrow spaces (Fig 7) made it difficult to count the preosteoblasts and osteoblasts independently.

Although the radioactive index in this zone was highest in association with rapid growth of bone in the youngest specimen and decreased with age (Fig 8), the activity of cells in this zone in the adult monkey appeared to be much higher than the activity in the intermediate zone. The adult monkey had not reached the age where condylar cartilage in monkeys practically disappears and becomes replaced by dense fibrous connective tissue, ${ }^{13}$ as has been also 


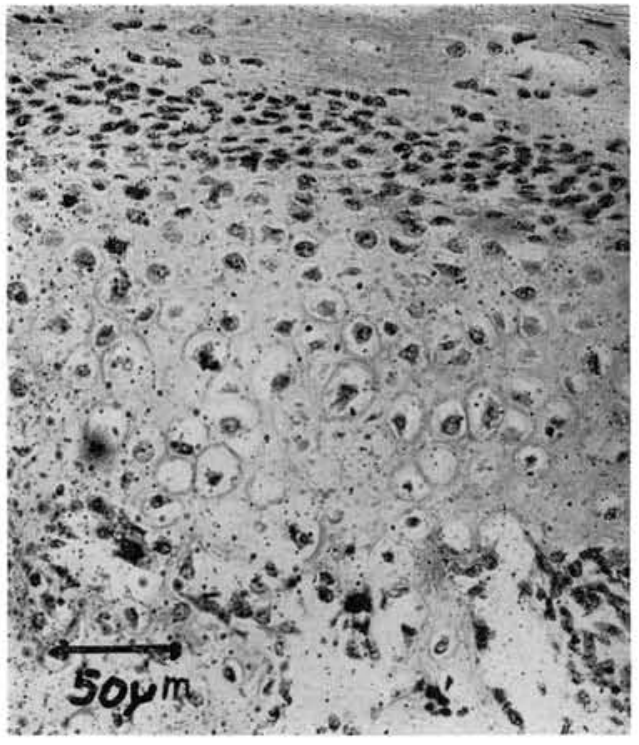

FIG 6.-Condyle of baby monkey. Labeled cells in zone of differentiation (zone 3) (orig mag $\times 260)$.

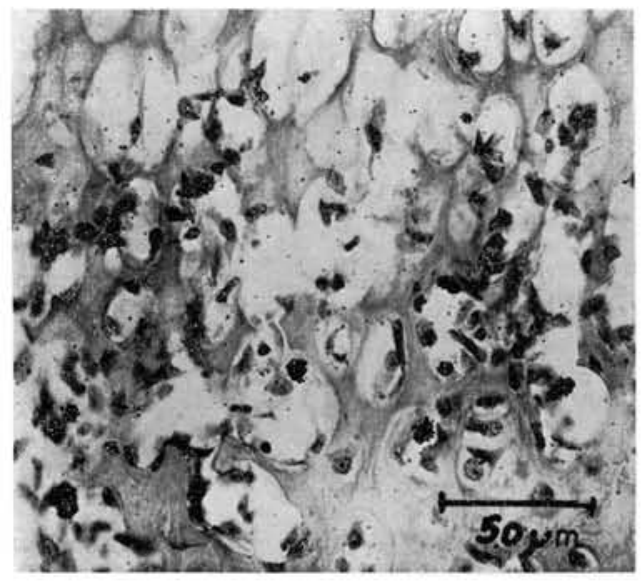

FIG 7.-Zone of erosion and new bone formation from baby monkey. Labeled preosteoblasts and osteoblasts (orig mag $\times 400$ ).

described for full-grown humans. ${ }^{14}$ The cortical layer of bone that caps the condyle in older monkeys had not developed. ${ }^{13}$ The cellular dynamics in the condyle of older monkeys has to be more fully investigated before definite figures can be established for strictly renewal turnover of cells in this zone of the condyle.

Recent histologic studies of the development of the temporomandibular joints in

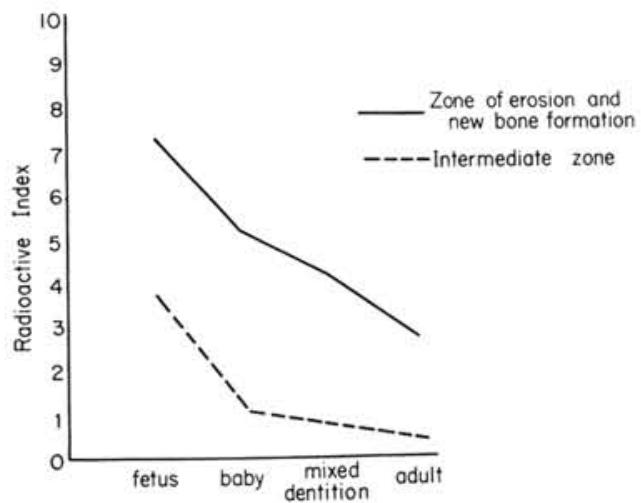

FIg 8.-Radioactive indexes related to age.

specimens from human beings ${ }^{1,15}$ have reported morphologic features closely resembling our observations in the rhesus monkeys. Studies in monkeys allow the use of investigative technics, such as autoradiography, which are unsuitable for studies in human beings. Morphologic similarities tend to encourage further studies of cellular dynamics by use of radioisotopes in rhesus monkeys, since it is probable that the physiology, as well as the anatomy, of the temporomandibular joint closely resembles that of human beings.

\section{Conclusions}

Two rhesus monkeys, aged $41 / 2$ months and 3 years, and one adult monkey of unknown age carrying a 4-month fetus, were injected with tritiated thymidine and killed about $1 \frac{1}{2}$ hours later.

Histologic sections and autoradiographs of the mandibular condyles of all the monkeys, including the fetus, were studied. The highest radioactive indexes were found in the intermediate zone of cartilage and in the zone of erosion and bone formation. The radioactive indexes of both these zones decreased gradually with age and appeared to be related both to growth and cell renewal. In the well-demarcated articular zone, there were a few scattered labeled cells of approximately equal number in all the age groups, which indicated cell renewal within this zone, independent of growth activity.

The histologic sections and the autoradiographs were prepared by Jean I. Simons and Virginia W. Hartog. at the Veterans Administration Hospital. Ann Arbor. Michigan. 


\section{References}

1. Baume, L.J.: Ontogenesis of the Human Temporomandibular Joint: I. Development of the Condyles, J Dent Res 41:1327-1339, 1962.

2. Cabrini, R., and Erausquin, J.: La Articulacion Temporomaxilar de la Rata, Rev Odont (Argentina) 29:385, 1941.

3. Collins, D.A.; Becks, H.; Simpson, M.; and Evans, H.M.: Growth and Transformation of the Mandibular Joint in the Rat: I. Normal Female Rat, Amer J Orthodont Oral Surg 32:431-442, 1946.

4. Cunat, J.J.; Bhaskar, S.N.; and WeinMANN, J.P.: Development of the Squamosomandibular Articulation in the Rat, J Dent Res 35:533-546, 1956.

5. Tonna, E.A.: The Cellular Complement of the Skeletal System Studied Autoradiographically with Tritiated Thymidine ( ${ }^{3} \mathrm{H}-\mathrm{TDR}$ ) during Growth and Aging, $J$ Biophys Biochem Cytol 9:813-824, 1961.

6. BLACKwood, H.J.: Growth of the Mandibular Condyle of the Rat Studied with Tritiated Thymidine, Arch Oral Biol 11: 493-500, 1966.

7. Dale, J.G.; Hung, A.M.; Pudy, G.; and WAGNER, D.: Autoradiographic Study of the Developing Temporomandibular Joint, J Canad Dent Ass 29:27, 1963.
8. Folke, L., and Stallard, R.E.: Cellular Kinetics within the Mandibular Joint, abstracted, Int Dent J 45:84, 1967.

9. Walker, B.E., and Leblond, C.P.: Sites of Nucleic Acid Synthesis in the Mouse Visualized by Radioautography after Administration of ${ }^{14} \mathrm{C}$ Labeled Adenine and Thymidine, Exp Cell Res 14:510-531, 1958.

10. Hurme, V.O., and Waganen, G.: Basic Data on the Emergence of Permanent Teeth in the Rhesus Monkey, Amer Philo Soc Proc 105:105-140, 1961.

11. ENGLer, W.O.; RAMFJoRd, S.P.; and HinIKRR, J.J.: Development of Epithelial Attachment and Gingival Sulcus in Rhesus Monkeys, J Periodont 36:44-56, 1965.

12. Ham, A.W.: Histology, 5th ed, Philadelphia: J.B. Lippincott Co., 1965.

13. RamFJord, S.P., and Hiniker, J.J.: Distal Displacement of the Mandible in Adult Rhesus Monkeys, J Prosth Dent 16:491-502, 1966.

14. Rushton, M.A.: Growth at the Mandibular Condyle in Relation to Some Deformities, Brit Dent J 76:57-68, 1944.

15. Furstman, L.: The Early Development of the Human Temporomandibular Joint, Amer J Orthodont 49:672-682, 1963. 